\title{
Os currículos praticados no cotidiano escolar na educação de surdos: entre a prescrição e a emancipação
}

\section{The curricula practiced in school daily life in the education of the deaf: between prescription and emancipation}

\section{Los currículos practicados en el cotidiano escolar en la educación de sordos: entre la prescripción y la emancipación}

Danielle Aguiar Fini ${ }^{1}$

Andréa Rosana Fetzner ${ }^{1}$

DOI: http://dx.doi.org/10.20435/serie-estudos.v23i48.1101

\begin{abstract}
Resumo: Este artigo apresenta pesquisa realizada em Programa de Pós-Graduação em Educação. Buscou-se compreender a relação entre as prescrições e as práticas curriculares de duas professoras dos anos iniciais do Colégio de Aplicação do Instituto Nacional de Educação de Surdos (INES). A metodologia envolveu a observação participante e entrevistas semiestruturadas. O estudo apresenta um breve panorama da história do INES, destacando seu espaço na educação de surdos no Brasil e reflexões acerca da importância do estudo curricular na educação de sujeitos surdos, considerando as especificidades da surdez e a importância da linguagem para a integração social e para a aprendizagem. Optando por uma análise de base intercultural, o resultado aponta para duas perspectivas curriculares de regulação: uma prescritiva e outra que ultrapassa a prescrição, por meio de práticas curriculares que valorizam os conhecimentos, referentes ao cotidiano, trazidos pelos estudantes e, portanto, regulações que contribuem para emancipação dos estudantes e dos docentes.
\end{abstract}

Palavras-chave: educação de surdos; INES; currículos praticados.

Abstract: This article presents a research carried out in the Graduate Program in Education. It was sought to understand the relationship between the prescriptions and curricular practices of two teachers from the initial years of the College of Application of the National Institute of Education of the Deaf (INES). The methodology involved participant observation and semi-structured

\footnotetext{
${ }^{1}$ Universidade Federal do Estado do Rio de Janeiro (UFRJ), Rio de Janeiro, Brasil.
} 
interviews.The study presents a brief overview the history of INES, with emphasis on its space in the education of the deaf in Brazil, considering the specificities of deafness and the importance of language for social integration and for learning. Opting for an intercultural analysis, the result points to two curricular perspectives of regulation: one prescriptive and one that goes beyond prescription, through curricular practices that value the knowledge, referring to the daily life, brought by students and, therefore, regulations that contribute to the emancipation of students and teachers.

Keywords: deaf education; INES; practical curricula.

Resumen: Este artículo presenta una investigación realizada en el Programa de Postgrado en Educación. Se buscó comprender la relación entre las prescripciones y las prácticas curriculares de dos profesoras de los años iniciales del Colegio de Aplicación del Instituto Nacional de Educación de Sordos (INES). La metodología implicó la observación participante y entrevistas semiestructuradas. O estudio presenta un breve panorama de la historia del INES, con destaque para su espacio en la educación de sordos en Brasil, reflexiones acerca de la importancia del estudio curricular en la educación de sordos, considerando las especificidades de la sordera y la importancia del lenguaje para la integración social y para el aprendizaje. optando por un análisis de base intercultural, y describe las perspectivas curriculares de regulación presentes en el cotidiano de dos clases de Ios años iniciales del INES, bajo la perspectiva de los estudios interculturales. El resultado apunta a dos perspectivas curriculares de regulación: una prescriptiva y otra que supera la prescripción, por medio de prácticas curriculares que valoran los conocimientos, referentes a lo cotidiano, traídos por los estudiantes y, por lo tanto, regulaciones que contribuyen a la emancipación de los estudiantes y de los docentes.

Palabras claves: educación de sordos; INES; curriculum practicados.

\section{INTRODUÇÃO}

Este artigo busca contribuir com as reflexões que tomam a interculturalidade como instrumento para o estudo curricular na educação de surdos, para isso, além de apresentar as diferentes práticas de regulação curricular presentes em duas turmas dos anos iniciais do Instituto Nacional de Educação de Surdos (INES), busca contribuir com o processo de compreensão, criação e desenvolvimento dos currículos praticados.

Para compreender o processo de criação e desenvolvimento dos currículos praticados, foi necessário observar a metodologia utilizada pelas professoras em sala de aula: a relação entre discentes e docentes, como surgiam os temas das aulas, quais conhecimentos eram visibilizados e quais eram silenciados, como era feita a organização da sala de aula, dos horários, dos murais, quais valores e comportamentos eram considerados importantes, como as avaliações eram realizadas, enfim, foi necessário compreender, o máximo possível, os aspectos que 
conformam o currículo escolar. A pesquisa foi realizada entre 2015 e 2016 e, no que se refere especificamente ao acompanhamento das turmas, foram 6 meses. Durante a pesquisa, além dos estudos teórico-práticos, foram realizadas conversas informais e entrevistas semiestruturadas. Foi possível constatar uma tensão entre as perspectivas curriculares: uma regulação de perspectiva mais prescritiva e outra que chamamos emancipatória, baseada na valorização de conhecimentos trazidos pelos estudantes.

O presente artigo traz um breve panorama da história do INES e seu espaço na educação de surdos no país, algumas considerações acerca da importância do estudo curricular na educação de surdos e, por fim, dados coletados na pesquisa de campo que apontam para o desenvolvimento de práticas curriculares entre a prescrição e a emancipação.

\section{INES E OS DESAFIOS INICIAIS DA EDUCAÇÃO COM OS SURDOS-}

O Instituto Nacional de Educação de Surdos foi a primeira escola de surdos no Brasil e, até os dias de hoje, é referência em âmbito nacional. De acordo com Rocha (2008), foi fundado em 1857 pelo professor surdo francês chamado Ernest Huet $^{2}$, responsável, também, por trazer a língua de sinais para o Brasil.

Atualmente, 2017, o Instituto está localizado na Rua das Laranjeiras, n. 232, Bairro das Laranjeiras, zona sul da cidade do Rio de Janeiro, e funciona em três turnos: manhã, tarde e noite. O Ensino Básico é oferecido no Colégio de Aplicação e abrange a Educação precoce, Educação Infantil, Ensino Fundamental I e II e o Ensino Médio. Além desses níveis de escolarização, o INES também proporciona aos estudantes, surdos e ouvintes, curso de Pós-Graduação Lato Sensu na área da Educação de Surdos. O Instituto realiza um atendimento alternativo e complementar para crianças que, além de surdas, tenham outros comprometimentos de ordem cognitiva, neurológica ou comportamental; esse serviço é oferecido no Centro de Atendimento Alternativo Florescer (CAAF).

\footnotetext{
${ }^{2}$ A grafia do nome de Ernest Huet é encontrada de duas formas: Hernest e Ernest. Optamos pela grafia utilizada pelo INES nos documentos consultados e no site. A grafia do nome Ernest referencia-se, também, no livro de Solange Rocha (2008). Segundo o Dicionário de Libras, a grafia seria Hernest. Dicionário disponível em: <http://www.dicionariolibras.com.br/website/artigo.asp ?cod=124\&idi=1\&moe=6\&id=2608>, consultado em de 26 outubro de 2017 .
} 
O ensino no INES é bilíngue ${ }^{3}$, em que a Língua Brasileira de Sinais (Libras) ${ }^{4}$ é a primeira língua, de instrução do currículo, e a língua portuguesa, a segunda língua, nas modalidades de leitura e escrita. A Libras, como primeira língua, objetiva a interação entre os diferentes sujeitos que estão presentes no processo de aprendizagem, proporcionando a troca de informações, exposição de seus desejos, vontades, opiniões; é a forma de comunicação entre os surdos entre si e com os demais sujeitos. Como principal fonte de comunicação e construção/ expressão do pensamento, é importante que o sujeito surdo aprenda a Libras desde cedo na escola e que sua família também aprenda para que a integração e o acesso à informação possam acontecer desde sua casa. No entanto, de acordo com a pesquisa de campo, a maioria dos familiares que são ouvintes e têm filhos surdos, não sabem a língua de sinais, e isso resulta em importante restrição à comunicação do e com o sujeito surdo.

O campo permitiu observar, também, que alguns estudantes tiveram acesso à língua de sinais tardiamente, resultando em um desenvolvimento diferente dos demais. O acesso à Libras o mais cedo possível, como condição fundamental para comunicação de forma mais elaborada, é defendido por Melletti e Kassar (2013, p. 197):

A criança surda precisa ser exposta, o mais cedo possível, ao contato com a língua, aprendendo a sinalizar tão rapidamente quanto as crianças ouvintes aprendem a falar - desenvolvendo suas capacidades cognitivas e sua competência linguística numa língua que lhe servirá depois como base para aprender a língua do grupo social majoritário no qual está inserida (o Português, no caso do Brasil), como segunda língua, tornando-se bilíngue.

\footnotetext{
${ }^{3}$ A abordagem bilíngue fundamenta-se na ideia de que a língua de sinais, língua viso-gestual, é a língua passível de aquisição pelos surdos em suas relações e práticas sociais, justamente por estar apoiada nos canais visual e gestual. Crianças surdas, quando têm a oportunidade de conviver com essa língua (filhos de pais surdos, ou com contato com surdos fluentes em língua de sinais), adquirem-na sem depender de qualquer treinamento específico. Assim, trata-se de uma língua plena, sob o ponto de vista linguístico, que pode ser adquirida naturalmente por sujeitos surdos (e ouvintes) quando as relações e práticas sociais propiciam esse contato (MELETTI; KASSAR, 2013, p. 197).

${ }^{4}$ Forma de comunicação e expressão, com o sistema linguístico de natureza visual-motora, e estrutura gramatical própria, que constituem um sistema linguístico de transmissão de ideias e fatos, oriundos de comunidades de pessoas surdas do Brasil (BRASIL, 2002).
} 
O INES se constitui, portanto, em espaço qualificado educacionalmente para a aprendizagem de Libras, uma vez que, além de oferecer diferentes níveis e modalidades de educação aos estudantes surdos, oportuniza a convivência com professores e funcionários surdos e ouvintes e a prática permanente da língua de sinais. Muitos estudantes chegam ao INES sem o conhecimento da língua de sinais e sem saber a língua portuguesa. Muitos pais também não sabem se comunicar com seus filhos por meio da Libras, resultando na falta de comunicação e informação aos sujeitos surdos sobre acontecimentos que fazem parte do cotidiano. Este é um dos aspectos que este trabalho constatou no cotidiano da escola e que será tratado na sequência deste trabalho, após a abordagem das circunstâncias que nos levaram a tomar o currículo praticado no INES como foco da pesquisa.

\section{POR QUE ESTUDAR AS PRÁTICAS CURRICULARES NA EDUCAÇÃO DE SURDOS?}

Em um primeiro contato com o Instituto para desenvolvimento da pesquisa, o orientador pedagógico do ensino fundamental foi consultado sobre qual seria uma questão de interesse para realização de uma pesquisa de mestrado com a Escola, nessa ocasião, o currículo foi indicado como demanda. Considerando essa questão, a pesquisa participante passou a ser estudada, assim como os movimentos iniciais para desenvolvimento do trabalho, entre eles a submissão ao conselho de ética e a revisão de pesquisas na temática.

Em seu desenvolvimento, a pesquisa se concentrou em tentar perceber as demandas curriculares dos sujeitos surdos e dos docentes, considerando as especificidades dessa modalidade de formação. Tomaram-se, então, os estudos curriculares como aqueles que envolvem desde questões didáticas até a compreensão mais ampla do projeto educativo em seus compromissos políticos e sentidos filosóficos (SACRISTÁN; GÓMEZ, 1998, p. 125).

A investigação propôs-se a perceber como se dão, por parte das professoras, as escolhas dos conhecimentos a serem abordados em sala de aula, na forma como a escola e a sala são organizadas e estruturadas, como são organizados os horários, a metodologia escolhida e os materiais utilizados. Entende-se que, para compreender o currículo de uma escola, é necessário observar e participar dela. Este estudo do currículo na educação de surdos, portanto, organizou-se para compreender como se desenvolvem as práticas curriculares em duas turmas do 
Instituto, e, como apoio para a análise, recorreu-se ao entendimento das relações entre experiência discente e currículo e entre prescrição e prática curricular.

Para compreensão dessas relações entre experiência e currículo e entre prescrição e prática curricular, tomaram-se os estudos da interculturalidade em Candau (2012) e da linguagem como invenção de caminho da cidadania (FREIRE, 2016, p. 56). Tanto no campo do currículo, quanto no campo da didática, os estudos interculturais têm apontado a necessidade de perceber as culturas presentes no cotidiano da sociedade e da escola como parte do processo de aprendizagem que se dá na escola. Reconhecer e trabalhar com as referências culturais dos estudantes, buscando compreendê-las e aprofundá-las, tem por objetivo transformar o espaço escolar de um lugar da transmissão do saber, visto de forma unilateral - de docentes que ensinam para o estudantes que aprendem -, para um espaço de trocas, onde as linguagens e as práticas sociais sejam tomadas de forma mais horizontalizada e, por consequência, as aprendizagens sejam percebidas como resultado de processos de trocas, não de imposições de uma cultura sobre as demais, num espaço de compartilhamento de culturas (SACRISTÁN; GÓMEZ, 1998). Destaca-se que, nas concepções interculturais, as culturas são entendidas como dinâmicas e não estáticas, fruto de interações, de construções sempre coletivas. Candau assim define a interculturalidade crítica, referência com a qual se orienta este trabalho:

Trata-se de questionar as diferenças e desigualdades construídas ao longo da história entre diferentes grupos socioculturais, étnico-raciais, de gênero, de orientação sexual, religiosos, ente outros. Parte-se da afirmação de que a interculturalidade aponta à construção de sociedades que assumam as diferenças como constitutivas da democracia e sejam capazes de construir relações novas, verdadeiramente igualitárias entre os diferentes grupos socioculturais, o que supõe empoderar aqueles que foram historicamente inferiorizados. (CANDAU, 2012, p. 127).

Nesse sentido, entende-se, neste trabalho, em relação à educação de surdos, a necessidade de perceber a comunidade surda como um grupo social que é, pela surdez, inferiorizado socialmente. As diferenças decorrentes da surdez precisam ser compreendidas como constituintes de suas identidades. Nessa perspectiva, um currículo intercultural representa o movimento de valorizar o pluralismo de referências culturais, com o respeito ao outro e às diferenças, tratando o sujeito 
surdo não como deficiente, mas como um sujeito diferente na sua forma de se comunicar, aprender, ler e compreender o mundo. Também é importante destacar que os estudantes surdos, tais quais os ouvintes, não se constituem em um grupo homogêneo, há pluralidade de experiências culturais familiares, de compreensões de si e do mundo que precisam ser compreendidas e ampliadas. Considerar o surdo como sujeito diferente não significa tratá-lo como incapaz, tampouco como uma comunidade homogênea, é necessário reconhecê-los em suas culturas próprias e a cultura que decorre de sua língua própria, a Libras.

Nesse contexto, Lima (2015, p. 52) afirma que "pensa-se no surdo a partir do ouvinte; este é o modelo no qual os surdos precisam se encaixar: ouvir, falar, usar de forma competente a língua oral". Este é um dos desafios: os ouvintes procuram enquadrar os sujeitos surdos em um padrão que consideram de normalidade, aquele que foge a esta regra (ouvinte), logo é rotulado como deficiente ou incapaz. Inserida em uma sociedade organizada por ouvintes, a escola tende a reproduzir práticas que colocam em destaque a ausência.

Contrapondo-se a essa perspectiva da ausência, é possível propor uma escola que reconheça as pluralidades, refletindo sobre um currículo escolar que esteja atento à realidade dos seus estudantes, levando em consideração suas culturas, sem tratá-los como defeituosos e incapazes. Aqui se destaca um segundo desafio: o reconhecimento da diferença entre os estudantes. A surdez não pode ser um pretexto para a redução de todos a uma mesma comunidade ou cultura, uma vez que cada família, cada história de vida traz uma vivência da surdez de forma diferente, como constatou a pesquisa em algumas situações presenciadas.

Para Freire (2016), o conhecimento é resultado de um processo que começa na compreensão da realidade do educando. A relação entre educador e educando deve ser baseada no diálogo, e não na intenção de transmissão de um conteúdo do professor ao estudante. Assim, as experiências, os saberes prévios dos estudantes, sua bagagem cultural, devem ser considerados. O professor precisaria dialogar com os estudantes, trocar ideias e não impor determinados conteúdos prescritos por quem não está presente na relação de aprendizagem que se efetiva na sala de aula. Essa relação é permeada pela linguagem que, no caso da surdez, tem desafios que lhes são próprios.

Ao tratar da linguagem, em seu livro Pedagogia da Esperança, diz Freire (2016, p. 56): 
Aí está uma das tarefas da educação democrática e popular, da Pedagogia da esperança-a de possibilitar nas classes populares o desenvolvimento de sua linguagem, jamais pelo bla-bla-blá autoritário e sectário dos "educadores", se sua linguagem que, emergindo da e voltando-se sobre sua realidade, perfile as conjecturas, os desenhos, as antecipações do mundo novo. Está aqui uma das questões centrais da educação popular - a da linguagem como caminho de invenção da cidadania". (grifos do autor) .

A linguagem é apontada por Freire (2016), portanto, como instrumento por meio do qual o sujeito desenvolve o diálogo e toma para si sua experiência e o mundo, refletindo-os e compreendendo-os. Pode-se destacar, assim, a importância da linguagem para os estudantes surdos, como instrumento de diálogo consigo e com o mundo, um diálogo que, desde a perspectiva freireana, pode vir a ser transformador. Dimensiona-se, assim, no contexto da surdez, a necessidade do indivíduo surdo de acesso à sua língua e, por isso, o INES é uma escola bilíngue, que proporciona aos seus estudantes a aquisição da Libras como primeira língua e o português escrito como segunda língua. A Libras é oferecida aos estudantes desde a Educação Infantil por professores surdos, proporcionando aos estudantes o direito à educação e à construção de sua identidade, por meio da convivência com surdos, colegas e professores.

Para colocar em prática um currículo em uma perspectiva intercultural, é importante visibilizar diferentes culturas e saberes, valorizando os conhecimentos prévios dos estudantes, por meio de uma relação horizontal entre professor e educandos. Freire (2000, p. 38) aborda sobre a valorização dos conhecimentos prévios dos estudantes:

[...] não posso de maneira alguma, nas minhas relações político-pedagógicas com os grupos populares desconsiderar seu saber de experiência feito. Sua explicação do mundo de que faz parte a compreensão de sua própria presença no mundo. E isso tudo vem explicitado ou sugerido ou escondido no que chamo de "leitura do mundo" que precede sempre a "leitura da palavra".

Dessa maneira, as escolas precisariam incorporar os diferentes saberes e as diferentes leituras de mundo como conteúdo curricular. É importante estudar sobre o currículo na educação de surdos, para que reflexões sobre o que estudar, como estudar, por que estudar, para que estudar possam ser respondidas por meio da compreensão da cultura surda frente à sociedade e das possibilidades e especificidades da língua de sinais para o processo de aprendizagem destes sujeitos. 
O indivíduo surdo não deveria se sentir inferior em relação aos ouvintes, mas o que ainda acontece na sociedade é a percepção da surdez como uma patologia. É importante que, na escola, promovam-se práticas que valorizem a cultura surda. Meletti e Kassar (2013, p. 191-2) destacam que:

[...] a surdez, em si, não torna a criança deficiente, este é um modo social de representá-la. Se a surdez for compreendida socialmente de outra forma, os indivíduos surdos poderão ocupar um lugar na sociedade, não ficando marginais. Busca-se, no caso dos surdos, fazê-lo ouvir e falar, mais do que desenvolvê-los como sujeitos, sejam eles crianças, adolescentes ou adultos; sua constituição como sujeito é tornada menos importante que suas habilidades para falar e ouvir. O foco está em habilidades que devem ser adquiridas mesmo quando se alega que a meta é o desenvolvimento da pessoa em todas as suas potencialidades.

Ou seja, o que ocorre é a imposição da cultura hegemônica (ouvinte) em relação à cultura dos surdos, pois, no momento em que professores, pais e sociedade, não respeitam a linguagem do sujeito surdo e buscam que ele fale, não estão promovendo a alteridade e o respeito à diferença. Em relação ao conceito de diferença, Skliar (2016, p. 5-6) indica que:

[...] o conceito de diferença não é utilizado como um termo a mais, dentro de uma continuidade discursiva, em que habitualmente se incluem outros como, por exemplo, "deficiência" ou "diversidade". Esses, no geral, mascaram e neutralizam as possíveis consequências políticas, colocam os outros sob um olhar paternalista e se revelam como estratégias conservadoras para ocultar uma intenção de normalização. A diferença como significação política é construída histórica e socialmente; é um processo e um produto de conflitos e movimentos sociais, de resistências às assimetrias de poder e de saber, de uma outra interpretação sobre a alteridade e sobre o significado dos outros no discurso dominante.

Logo, a reflexão entre currículo e diferença provoca a compreensão dos conflitos entre as diferentes culturas e de diferentes grupos sociais, o que indica a necessidade de provocar o debate das práticas curriculares diante do reconhecimento do sujeito surdo em sua história, que envolve discriminações e lutas, e também enquanto sujeitos plurais que estão ligados por uma identidade em comum: a surdez, mas que, assim como os ouvintes, não se resumem a esta sua característica identitária (ser surdo ou ouvinte). 


\section{CURRÍCULOS PRATICADOS NO INES: ENTRE A PRESCRIÇÃO E A EMANCIPAÇÃO}

Ao pesquisar o processo de criação e desenvolvimento dos currículos praticados por duas professoras dos anos iniciais do Colégio de Aplicação do INES, o trabalho buscou identificar o lugar em que essas práticas curriculares situavam-se: entre a regulação e a emancipação. Esta análise baseou-se nos estudos de Oliveira (2005), que, considerando os estudos de Sousa Santos (1995), identifica duas formas de regulação, uma de perspectiva liberal, "perversa, de controle sobre as manifestações do mais fraco, sob a alegação de que são formas selvagens e inadequadas a serem superadas, que prejudicam as possibilidades da emancipação democratizante" (OLIVEIRA, 2005, p. 27) constituindo-se, portanto, na regulação como domínio, subalternização, negação do outro que não lhe seja semelhante. A autora também identifica a regulação desde perspectivas de equalização social, voltadas "à emancipação, limitando o poder do mais forte, democratizando as relações de poder" (OLIVEIRA, 2005, p. 27), seriam essas regulações, portanto, positivas para a promoção da equidade social.

O entendimento da regulação, nessas diferentes perspectivas, é importante para que seja possível perceber as leis, as normas e as práticas de forma mais complexa, entendendo que uma medida de determinada natureza não é ruim ou boa por si só e, portanto, precisa ser percebida em um contexto complexo, onde a "pergunta para que/quem serve?" Torne-se uma pergunta orientadora. Com este entendimento, Oliveira (2005) propõe a ideia de que práticas de regulação que busquem garantir os direitos dos mais fracos podem gerar a emancipação.

No que se refere à análise dos conhecimentos escolares, este estudo recorreu à Sousa Santos (2009), no entendimento de que a construção da emancipação decorre do reconhecimento da pluralidade de conhecimentos, ou seja, da "ecologia de saberes". De acordo com o autor (SOUSA SANTOS, 2009, p. 45), a ecologia de saberes tem como premissa "a ideia da diversidade epistemológica do mundo, o reconhecimento da existência de uma pluralidade de formas de conhecimento além do conhecimento científico". A ecologia de saberes se refere à valorização dos diferentes conhecimentos, e não apenas dos científicos, mas os conhecimentos da população, dos povos indígenas, dos camponeses, dos marginalizados socialmente. 
Para isso, considerando também os estudos de Freire (2016) já citados neste trabalho, o professor precisa conversar com os estudantes e conhecer suas questões de vida, suas curiosidades. Questiona-se, portanto, o papel docente quando este é reduzido à transmissão de conteúdos que estão listados nos currículos prescritos. Nessa perspectiva, Sacristán e Gómez (1998, p. 64) indicam que:

Os/as alunos/as devem participar na aula trazendo tanto seus conhecimentos e concepções como seus interesses, preocupações e desejos, envolvidos num processo vivo, em que o jogo de interações, conquistas e concessões provoque, como em qualquer outro âmbito da vida, o enriquecimento mútuo.

De acordo com a pesquisa de campo, os conhecimentos abordados nas salas de aula observadas, são os formais (das disciplinas) e os conhecimentos que os estudantes traziam de seus cotidianos. Existe um documento, que é chamado de planejamento do ensino pela orientação pedagógica e, conforme demonstrará o relato do trabalho no campo, é compreendido como o documento curricular do INES. Esse documento é proposto pela orientação pedagógica e apresenta os objetivos e os conteúdos a serem trabalhados a cada bimestre.

Embora vivenciassem a cobrança para que os conteúdos do planejamento de ensino fossem cumpridos (regulação que tentava manter as professoras subalternizadas ao encaminhamento curricular e não Ihes permitir uma participação mais ativa), as professoras conseguiam desconsiderar, em alguns momentos, esse controle e abordavam conhecimentos e questões que os estudantes traziam de suas realidades e, algumas vezes, conseguiam articular os conhecimentos formais com as realidades dos discentes.

Nas entrevistas e conversas realizadas, as professoras Cláudia e Amanda 5 , ao serem questionadas sobre como faziam o levantamento dos temas das aulas, responderam que seguiam o planejamento de ensino dado pela escola, seguindo os conteúdos propostos, mas tentavam relacionar esses conteúdos com a realidade dos estudantes,

[...] eu me baseio no currículo do 4 o ano, aqui nós precisamos segui-lo, mas diante de algumas questões que são levantadas na minha sala, é... as vezes a gente muda as estratégias, né? [...] uma aluna minha viajou pra Minas Gerais. Os estados do Brasil não faziam parte do currículo, apenas a região sudeste e tudo que envolve o Rio de Janeiro. Nada mais. E aí eu achei

\footnotetext{
${ }^{5}$ Nomes fictícios, por opção das autoras do trabalho.
} 
interessante, porque ela já tinha a questão da noção de tempo, o tempo que ela demorou no avião, que era longe, ela já tinha ido prá lá de avião, já tinha ido de carro, então ela fez essa comparação das horas: quanto tempo de carro, quanto tempo de avião, o que ela viu no caminho, então, daí, eu já tirei pra ensinar pra eles, altura e altitude que era uma coisa que eles não tinham conhecimento, a gente ainda não tinha trabalhado relevo e eu comecei a explicar. Expliquei a questão que era um outro estado, mas que fazia parte de uma mesma região e, a partir disso, eles começaram a aprender todos os estados do Brasil. (Professora Cláudia, 4음 ano, conversa em 17 de outubro de 2016).

[...] embora tenha os...os... conteúdos, a gente tenta mesclar com algumas coisas que estão passando no momento, seja da política, seja uma doença, uma epidemia, seja um projeto sobre a copa ou as olimpíadas, a gente tenta fazer essa união e com Português também as vezes a gente consegue através de texto, interpretação textual, ao fazer quadrinhos, a gente tenta associar os gêneros, no caso da língua portuguesa com alguma coisa que esteja dando no momento, pra não ficar um currículo tão dissociado... e eles também perguntam, trazem muitas coisas pra sala de aula... "ah! eu vi tal coisa na televisão" e não entendem. Então a gente aproveita pra explicar, através de um texto. (Professora Amanda, 5o ano, conversa em 8 de novembro de 2016).

Destaca-se que a professora Cláudia indica que o currículo é o que propõe o planejamento de ensino, e esse entendimento se mostrou comum na escola. A professora destacou também que, por meio de uma experiência vivenciada por uma das estudantes, ela abordou conhecimentos que não constavam no planejamento de ensino, ultrapassando-o. A professora Amanda, mesmo seguindo os conteúdos propostos pelo planejamento de ensino, relaciona esses conteúdos com a realidade dos alunos, contextualizando-os, quando consegue. A busca de referência para os conteúdos, nas experiências dos estudantes, não deixa de ser um certo exercício da regulação enquanto emancipação, mesmo que, ao mesmo tempo, essas professoras encontrem-se pressionadas a seguir o planejamento de ensino proposto pela escola, planejamento este construído de forma não participativa, portanto, atuando como regulação que subalterniza.

Outras práticas de regulações que buscavam a equidade e, portanto, a emancipação, eram propostas pelas professoras por meio de organizações muito simples, por exemplo, quando a professora Cláudia escolhia, a cada dia, um estudante diferente para ficar responsável pela chave da sala de aula. Sempre que 
a turma ia para outro espaço, como por exemplo, para oficina de Matemática ou Ciências, realizadas em outras salas, um estudante diferente ficava responsável pela chave da sala de aula, era uma ação da professora que, segundo sua própria avaliação, ajudava os estudantes a terem responsabilidades com o espaço (dados do diário de campo, em 19 de setembro de 2016).

Outras observações realizadas se referiram às normas de funcionamento do Colégio de Aplicação do INES, entre elas, alguns procedimentos disciplinares, como: respeitar os colegas, professores e funcionários, não ter atitudes preconceituosas, atenção nos horários, cuidados e zelo pelos equipamentos, prédio e materiais didáticos, entre outros. Essas normas são ensinadas pelas docentes para que os discentes aprendam valores e comportamentos importantes para a vida em uma sociedade democrática.

Durante a pesquisa de campo, observou-se que, na turma do 5o ano, com a professora Amanda, havia apenas uma menina e, às vezes, os meninos zombavam dela, por vários motivos: ou porque a professora Amanda chamava sua atenção, ou porque ela, ao responder alguma questão, respondia de forma errada, ou porque gostava muito de conversar e não prestava atenção na aula, qualquer outro motivo servia. A professora Amanda, por diversas vezes, chamava a atenção dos meninos, dizendo que eles tinham que respeitar a colega, pois rir e zombar eram atitudes desrespeitosas e preconceituosas. O mesmo fazia esaa professora em relação a um dos meninos que estava acima do peso, com os colegas que dele zombavam; assim, a professora conseguia coibir as atitudes que constrangiam a menina e esse menino, em especial.

Portanto percebe-se que o currículo escolar é muito mais do que os conteúdos das disciplinas tradicionais, abrange tudo que está relacionado à sala de aula: comportamentos desejados pelas docentes, valores ensinados, a forma como os murais são construídos, como são realizadas as atividades em sala de aula, como é a arrumação da sala de aula, se tem mapas, livros, como os horários estão organizados, se existe prioridade de alguma disciplina ou não, como são elaborados os planejamentos, planos de ensino, relação professor e estudante, enfim, tudo o que se refere ao processo de ensino-aprendizagem.

A professora Amanda também propunha desenvolver atividades que buscavam, por meio da regulação, a emancipação dos estudantes. Uma situação observada foi quando ela estudava com a turma os números decimais (conteúdo 
do planejamento de ensino), a professora aproveitou e ensinou os estudantes a fazerem os cálculos de suas notas e média final, para saber se ficariam em recuperação ou não. Em conversa informal com a professora Amanda, ela destacou que ensinou esses cálculos para que eles pudessem ter independência e autonomia no próximo ano, já que iriam para o 60 ano, e nesse segmento são vários professores (dados do diário de campo, em 8 de novembro de 2016).

Regras, valores, comportamentos ensinados e a autoridade exercida pelas docentes nem sempre podem ser colocados como uma regulação de perspectiva liberal ou subalternizante, pois as professoras, ao ensinar atitudes de organização, de respeito e responsabilidade, por exemplo, objetivam a formação para a emancipação. Nesse sentido, Oliveira (2005, p. 110) aborda que,

[...] esse exercício de autoridade nem sempre pode ser encarado como negativo ou reprodutor, na medida em que as professoras muitas vezes introduzem valores que contribuem exatamente para a ruptura da legitimidade da norma fundamentada em processo de regulação não-emancipatórios e criam formas de organização e regulação que contribuem para a emancipação social.

Não cabe, portanto, classificar ações que buscam regular ou controlar como necessariamente negativas, porque muitas vezes para emancipar são necessárias regulações que fortaleçam os mais fracos na relação estabelecida, seja com os colegas, com os professores ou na sociedade de forma mais geral.

Quanto à organização dos murais, foram observados, durante a pesquisa de campo, os murais das salas de aula e os murais dos corredores da escola. Os murais das salas de aula do 4ㅇ ano e do 5 ano continham trabalhos dos estudantes, realizados em atividades em sala de aula. No mural da sala do 5으 ano, havia cinco atividades de histórias em quadrinhos produzidas pelos estudantes. O tema do mural era Histórias com cumprimentos, saudações e apresentações. Perguntada sobre a origem dos temas apresentados, a professora relatou que, ao entrar no Facebook dos seus estudantes, percebeu muitos erros na escrita de algumas palavras referentes a saudações e cumprimentos, por isso resolveu elaborar um projeto com esse tema e trabalhar de forma contextualizada em sala de aula. Amanda aproveitou a oportunidade e efetivou o projeto propondo atividades de histórias em quadrinhos (conteúdo proposto pelo planejamento de ensino do 5 ano), assim, conseguiu trabalhar um tema que, na sua avaliação, 
atendia à necessidade de seus estudantes, de uma forma lúdica com a qual eles se envolveram e, ao mesmo tempo, cumpriu alguns dos conteúdos propostos pelo Instituto. Nesse projeto, a professora baixou um aplicativo no qual ela e os estudantes eram os personagens das histórias em quadrinhos, e isso despertou o interesse dos estudantes. Portanto, ao abordar um conteúdo do planejamento de ensino, a docente conseguiu contextualizá-lo ao propor atividades que possuíam sentido aos estudantes, tornando-os significativos (dados do diário de campo, em 12 de setembro de 2016).

Os murais dos corredores eram elaborados em projetos realizados pelos docentes do Ensino Fundamental I ou atividades referentes a alguma data comemorativa. As temáticas encontradas foram as Olimpíadas e o Dia do Surdo. No dia 26 de setembro, comemora-se o Dia do Surdo e, por isso, o mural dos corredores, naquele mês, foi elaborado pelos estudantes do 1 으 ao 5 o ano por meio de frases e desenhos em que expressavam orgulho em serem surdos.

As salas de aula tinham duas conformações distintas: em dia de provas ou testes, os estudantes ficavam um atrás do outro e, em dias de aula sem provas ou testes, a sala era organizada de modo que os alunos pudessem interagir.

Nem sempre, o que o planejamento de ensino da escola propõe pode ser cumprido, pois o estudante precisa compreender o conhecimento proposto e, algumas vezes, não tem condição para isso, conforme aborda a professora Cláudia em um trecho de sua entrevista,

[...] às vezes eu elaboro uma aula partindo de um, de um... partindo do currículo, aí eu chego aqui e eu vejo que o aluno não tem aquele conhecimento prévio pra poder adquirir aquele determinado conteúdo. Então dali você já pega uma outra coisa pra começar a fazer o trabalho, mas principalmente com os surdos surgem muitas questões diárias de coisas que eles não possuem o conhecimento ou então eles chegam com alguma dúvida. (Professora Cláudia, 4ㅇan ano, conversa em 17 de outubro de 2016).

Portanto percebe-se que os conteúdos propostos pelo planejamento de ensino do Instituto não atendem a necessidade de alguns estudantes, e, por isso, a docente tem que percorrer outros caminhos, ocasionando uma transformação no prescrito. Desse modo, é possível perceber que o currículo praticado não é o que está no papel, mas o que é vivido diariamente em sala de aula, na relação professor e estudante. Nessa perspectiva, Goodson (2013, p. 22) aponta que "a 
dicotomia entre o currículo adotado por escrito e o currículo ativo, tal como é vivenciado e posto em prática, é completa e inevitável". O autor reafirma as contribuições de Sacristán e Gómez (1998), ao apontarem que o currículo, praticado diariamente no espaço escolar, não será vivenciado da mesma maneira que os documentos curriculares ou pelo currículo prescrito, pois os acontecimentos de uma sala de aula são imprevisíveis, as formas de compreensão são diversas, vários são os questionamentos e, por meio do diálogo, fundamentado em uma relação horizontal com os estudantes, é que o currículo se efetiva. É por meio do diálogo que surgem outros temas de aula, superando a perspectiva de um currículo que se reduz ao que é prescrito, orientado, indicado.

Para superar essa pedagogia da homogeneização, é necessário refletir sobre práticas curriculares, construídas por meio do diálogo entre professor e estudantes, ultrapassando as prescrições e valorizando a necessidade dos estudantes. Nesta pesquisa, as práticas curriculares se mostraram, em alguns momentos, articuladoras desses conhecimentos. A regulação, de perspectiva liberal, pôde ser percebida quando as professoras eram cobradas, ou se cobravam, pelo cumprimento dos conteúdos e objetivos propostos pelo planejamento de ensino, e assim abordavam conhecimentos em sala de aula, que nem sempre atendiam as necessidades de todos e que, ao mesmo tempo, atropelavam processos de aprendizagem que estavam em andamento. Também foi possível perceber a regulação a serviço da emancipação, quando as professoras buscavam conduzir, nas práticas escolares, os estudantes a atitudes participativas e respeitosas.

Destaca-se, também com base nas observações realizadas na escola, que, além do desafio de trabalhar com o cotidiano e a cultura dos sujeitos surdos, é necessário reconhecer as individualidades desses sujeitos. O conhecimento da Libras entre eles é muito diferente. Acompanhou-se, no dia 22 de novembro de 2016, no INES, uma reunião com os responsáveis, realizada pela professora Cláudia, para entregar os boletins e falar sobre a média dos estudantes, a pontuação necessária para poder ser aprovado para o 5a ano, como funcionava a recuperação, o que foi estudado no 3 o bimestre e sobre as avaliações, de uma maneira geral. Na reunião, estavam presentes cinco mães e dois pais. Nesse momento, por meio de consulta aos responsáveis, foi possível verificar que apenas duas mães sabiam Libras e estavam fazendo o curso, aqueles que informaram não saber Libras, questionados sobre como era a comunicação em casa com os filhos, responderam que 
era precária, por meio de gestos, de olhares e que a maior dificuldade era para estudar, pois eles não conseguiam explicar os conhecimentos abordados em sala de aula (dados do diário de campo, 2016).

Essa informação permite compreender que, quando as professoras apontavam que os estudantes chegavam ao INES sem o conhecimento de nenhuma língua e que faltava o apoio dos pais, parte dessas questões (por vezes comuns em escolas de ouvintes), na educação de surdos é mais grave, uma vez que impede o compartilhamento de uma mesma língua. Os estudantes surdos ficam restritos ao espaço escolar para terem acesso à compreensão de informações básicas do cotidiano, e não apenas aos conhecimentos formais.

Na turma da professora Cláudia, um dos estudantes chegou ao INES há dois anos e apresentava dificuldades na leitura e escrita da língua portuguesa. Sua mãe informou que eles moravam em Brasília e seu filho estudava numa escola que se dizia inclusiva, porém, nessa escola, ele não interagia com ninguém, ficava isolado e, segundo a mãe, não aprendia. Percebendo essas dificuldades, ela e o marido decidiram se mudar para o Rio de Janeiro e matriculá-lo no INES, para que ele pudesse aprender Libras. Os pais disseram que ele não aceitava ser surdo. Depois que ele começou a estudar no INES, passou a conviver com crianças também surdas e agora ele já se entende como sujeito surdo e desenvolveu-se bastante em relação à aprendizagem da língua de sinais e também na leitura e escrita da língua portuguesa (diário de campo, 2016). Para o sujeito surdo, aprender a Libras é ter direito à comunicação, como ação para construção de sua identidade, aprender a língua portuguesa é ter assegurado seu acesso à leitura e escrita. 0 fato de muitos aprenderem a língua de sinais tardiamente impõe determinadas condições à aprendizagem, pois, por meio da linguagem, é que o pensamento é estruturado e é a base de qualquer comunicação: "el lenguage nace de la necesidad de comunicarse y pensar"6 (VYGOTSKI, 1983, p. 125). A falta de acesso à linguagem apropriada reflete no rendimento escolar e na falta de entendimento de assuntos que, para ouvintes, podem ser comuns.

Em 7 de junho de 2016, na turma do 40 ano da professora Cláudia, havia desenhos e atividades sobre as Olimpíadas, tanto na sala de aula quanto nos corredores. Tratava-se de um projeto que os professores elaboraram até o mês

\footnotetext{
${ }^{6} \mathrm{~A}$ linguagem surge da necessidade de se comunicar e pensar.
} 
de agosto, no entanto, antes da execução desse projeto, a professora Cláudia informou que estava propondo atividades relacionadas às Olimpíadas, pois, em uma conversa com a turma, os estudantes perguntaram por que as férias seriam em agosto e não em julho (como todos os anos). A professora, ao explicar que seria diferente devido às Olimpíadas, perguntou aos alunos o que eles sabiam sobre Olimpíadas. Alguns não souberam responder e outros sabiam do que se tratava. É preciso compreender o quanto o acesso a conhecimentos comuns aos ouvintes, para alguns surdos, é dificultado, porque uma criança que ouve, ao assistir à televisão, tem acesso às informações do que está acontecendo no país, e, assim, pode saber da agenda proposta pela mídia, não apenas na televisão, mas nos diversos meios de comunicação, o mesmo não acontece com os surdos.

Se os pais não conversam com seus filhos, não explicam os acontecimentos sociais, os sujeitos surdos ficam sem compartilhar interpretações em seu grupo familiar, por isso seria importante, não só o acesso o mais cedo possível à Libras, mas também que todos os canais televisivos e todos os programas incluíssem um intérprete de Libras, para que de fato eles pudessem acessar informações que são comuns aos ouvintes e estar incluídos não somente nas escolas, mas no compartilhamento de acontecimentos da sociedade. É necessário propor a inclusão não apenas na escola, mas na sociedade de um modo geral. De acordo com a pesquisa de campo, um dos desafios para a educação de surdos é disponibilizar informações a esses sujeitos, ampliar seus conhecimentos em relação aos acontecimentos que fazem parte do cotidiano, estimular que eles questionem mais, enfim, promover a compreensão do contexto social, cultural e econômico em que eles vivem.

\section{CONCLUSÕES PROVISÓRIAS}

Este artigo apresentou pesquisa desenvolvida com o INES, a partir da demanda do Instituto para que fosse estudado o seu currículo no ensino fundamental. A pesquisa, realizada com abordagem qualitativa e observação participante, além da revisão bibliográfica e documental, acompanhou duas professoras dos anos iniciais da instituição por seis meses e dedicou-se à compreensão das práticas docentes entre a prescrição curricular e os currículos praticados. Buscou-se compreender as práticas curriculares entre os processos de regulação liberais, identificados por Oliveira (2005) como aqueles que tratam de conformar os subalternos em suas posições de subalternidade, e os processos de regulação que buscam garantir mais 
autonomia e participação aos que se encontram em posição de subalternidade e, portanto, contribuiriam com a emancipação.

A pesquisa investigou as relações entre as docentes, os estudantes, os conhecimentos escolares e os conhecimentos que decorrem das experiências dos estudantes, encontrando um cenário onde as professoras entendem-se pressionadas, pela Instituição, a trabalharem com os conhecimentos prescritos no planejamento de ensino (apresentado pelo INES aos professores no início do ano letivo). A pressão se dá pelas cobranças em reuniões pedagógicas e por um certo sentido de necessidade de cumprimento da prescrição de conhecimentos pelas próprias professoras. A situação é complexa, entre outras questões, porque os estudantes surdos lidam com dificuldades de comunicação social por meio da restrição ao uso da Libras, decorrente do desconhecimento desta, algumas vezes em casa e, muitas vezes, na sociedade.

O Instituto é o espaço social onde a convivência dos surdos entre si facilita a aprendizagem da língua de sinais e o reconhecimento identitário dos surdos. As prescrições curriculares envolvem a aprendizagem da língua portuguesa e isto, associado com a proposição de outros conteúdos específicos, por meio do planejamento de ensino (documento curricular prescritivo dos conteúdos a serem ensinados), acaba por limitar a ação das professoras, segundo suas próprias avaliações. Mesmo assim, as professoras tentam relacionar os temas trabalhados aos estudos propostos pelo planejamento de ensino, e, em algumas situações, conseguem trabalhar questões que ampliam a visão dos estudantes sobre o que percebem do mundo, por meio da participação da experiência deles no ensino proposto pelas professoras.

No cotidiano das turmas pesquisadas, os currículos eram criados e desenvolvidos por meio da valorização dos diferentes conhecimentos, tanto os formais, que estão nos documentos curriculares, como os conhecimentos que os estudantes traziam de suas realidades e não constavam nos documentos curriculares, resultando em atividades que conseguiam ultrapassar os conhecimentos propostos. Porém, ao serem cobradas pelo cumprimento de conteúdos e objetivos do planejamento de ensino, as professoras demonstravam preocupação com o tempo para cumpri-los e, assim, eram levadas, algumas vezes, a abordar em sala apenas os conhecimentos que nem sempre eram relevantes para os estudantes, resultando em aulas pouco atrativas. 
A percepção quanto ao resultado dos currículos praticados é de que, quando as aulas ocorriam por meio de conhecimentos que não tinham sentido para os estudantes, geralmente com aulas expositivas, estes demonstravam pouco interesse e se dispersavam, no entanto, quando as aulas eram feitas por meio do diálogo, com atividades coletivas e conhecimentos relevantes, o resultado era o interesse e a aprendizagem. É importante destacar também que, nos dias de prova, os estudantes demonstravam preocupação e ansiedade, pois as avaliações eram feitas por meio de testes e provas, em que os estudantes não podiam consultar, nem interagir com os outros. Durante a observação participante foi possível constatar regulações que, desde o lugar de coordenação da escola e, por vezes, já incorporadas pelas próprias docentes, se exerciam para que o planejamento proposto fosse cumprido sem a valorização e reconhecimento das necessidades emergentes dos estudantes. Ao mesmo tempo foram percebidas práticas de regulação mais orientadas pela emancipação, neste caso, das professoras para com os estudantes, buscando assegurar um ambiente acolhedor para os mesmos, e onde suas experiências pudessem ser a fonte dos conhecimentos escolares.

\section{REFERÊNCIAS}

BRASIL, Lei n. 10.436, de 24 de abril de 2002. Disponível em: <http://www.planalto.gov. br/ccivil_03/leis/2002//10436.htm>. Acesso em: 30 jul. 2017.

CANDAU, Vera M. (Org.). Didática crítica intercultural: aproximações. Petrópolis, RJ: Vozes, 2012.

DICIONÁRIO DE LIBRAS. [s.d.]. Disponível em <http://www.dicionariolibras.com.br/ website/artigo. asp?cod=124\&idi=1\&moe=6\&id=2608>. Acesso em: 26 out. 2017.

FREIRE, Paulo. Pedagogia da esperança: um reencontro com a Pedagogia do Oprimido. 23. ed. Rio de Janeiro: Paz e Terra, 2016.

. Pedagogia da indagação: cartas pedagógicas e outros inscritos. São Paulo: Editora da Unesp, 2000.

GOODSON, Ivor F. Currículo: teoria e história. 14. ed. Petrópolis, RJ: Vozes, 2013.

LIMA, Camila Machado de. Educação de surdos: desafios para a prática e formação de professores. Rio de Janeiro: Wak, 2015.

MELETTI, Silvia Márcia Ferreira; KASSAR, Mônica de Carvalho Magalhães. Escolarização de alunos com deficiências: desafios e possibilidades. Campinas, SP: Mercado de Letras, 2013. 
OLIVEIRA, Inês Barbosa de. Currículos praticados: entre a regulação e a emancipação. 2. ed. Rio de Janeiro: DP\&A, 2005.

ROCHA, Solange. O INES e a educação de surdos no Brasil. 2. ed. Rio de Janeiro: INES, 2008. v. 1.

SACRISTÁN, J. Gimeno; GÓMEZ, A. I. Pérez. 4. ed. Compreender e transformar o ensino. Porto Alegre: Artmed, 1998.

SKLIAR, Carlos. A surdez: um olhar sobre as diferenças. 8. ed. Porto Alegre: Mediação, 2016. SOUSA SANTOS, Boaventura de; MENESES, Maria Paula. Epistemologias do sul. Coimbra, Portugal: Edições Almedina, 2009.

1995.

. Pela mão de Alice: o social e o político na pós-modernidade. São Paulo: Cortez,

VYGOTSKI, L. S. Fundamentos da defectologia. Moscou: Editorial Pedagógica, 1983. v. 2.

\section{Sobre as autoras:}

Danielle Aguiar Fini: Mestre em Educação pela Universidade Federal do Estado do Rio de Janeiro (UNIRIO). Graduada em Pedagogia (Habilitação em Supervisão Escolar, Administração Escolar e Orientação Educacional) pela Universidade Estadual do Rio de Janeiro. Docente no Instituto Nacional de Educação de Surdos. E-mail: dannyfini@hotmail.com

Andréa Rosana Fetzner: Doutora em Educação pela Universidade Federal do Rio Grande do Sul (UFRGS). Mestre em Educação e licenciada em Ciências Sociais pela Universidade do Vale do Rio dos Sinos (UNISINOS). Coordenadora do Programa de Pós-Graduação em Educação- Mestrado e Doutorado (IPPGEDU); professora associada na Universidade Federal do Estado do Rio de Janeiro (UNIRIO). E-mail: akrug@uol.com.br

\section{Recebido em outubro de 2017}

Aprovado em janeiro de 2018 
